\title{
Highly Compact MIMO Antenna System for LTE/ISM Applications
}

\author{
Lingsheng Yang, Tao Li, and Su Yan \\ Jiangsu Key Laboratory of Meteorological Observation and Information Processing, \\ Nanjing University of Information Science \& Technology, Ningliu Road, Nanjing 210044, China
}

Correspondence should be addressed to Lingsheng Yang; ylsinchina@163.com

Received 13 June 2015; Revised 24 August 2015; Accepted 6 September 2015

Academic Editor: Miguel Ferrando Bataller

Copyright (C) 2015 Lingsheng Yang et al. This is an open access article distributed under the Creative Commons Attribution License, which permits unrestricted use, distribution, and reproduction in any medium, provided the original work is properly cited.

Planar monopole antenna is proposed as the antenna element to form a compact dual-element multiple-input-multiple-output (MIMO) antenna system for LTE2300 (used in Asia and Africa) and ISM band operation. The system can cover a $310 \mathrm{MHz}(2.20-$ $2.51 \mathrm{GHz}$ ) operating bandwidth, with the total size of $15.5 \mathrm{~mm} \times 18 \mathrm{~mm} \times 1.6 \mathrm{~mm}$. Measured isolation higher than $16 \mathrm{~dB}$ is obtained without any specially designed decoupling structures, while the edge-to-edge element spacing is only $7.8 \mathrm{~mm}(0.08 \lambda$ at $2.20 \mathrm{GHz})$. Radiation characteristics, correlation coefficient, and the performance of the whole system with a metal sheet and a plastic housing show this system is competitive for practical MIMO applications. The antenna element is further used to build an eight-element MIMO antenna system; also good results are achieved.

\section{Introduction}

MIMO antenna systems are widely used in modern wireless terminals $[1,2]$. The use of multiple antennas can increase the data rate without extra need of bandwidth and power levels. However, in practical mobile terminal design, the space for antenna system is highly limited. When elements are close to each other, strong electromagnetic coupling will occur. How to obtain a compact MIMO antenna system with a wide bandwidth while maintaining adequate isolation between the elements becomes a challenging task [3-5].

Electromagnetic band-gap (EBG) structures $[6,7]$ are used to suppress the surface wave and enhance the isolation. But for this method, the size of the EBG elements is always larger than $0.1 \lambda_{0}$ and the structure is complicated in practical design and can affect the radiation characteristics of the whole system. Defected ground plane structures (DGS) are used in [8]; the performance will be deteriorated when placed closely to conductive objects. Elements are placed orthogonally in [9]; the arrangement makes the antenna elements have orthogonal polarization which can reduce the mutual coupling between the antennas. Besides the arrangement of antenna elements, placing metal strips between elements $[10,11]$, changing the structure of the ground [12-14], and adding lumped element on the ground [15] are used to further improve the isolation of the whole system. In [16, 17], filtering structures like slotted meander-line resonators and modified serpentine structure are used to enhance the isolation between two microstrip patch antennas. The structures are complicated in design and only effective at single resonant frequency, and the total systems are large in size and not wide in bandwidth (60 MHz for [17]).

In this paper, two symmetric planar monopole antennas are used to form the MIMO antenna system. The total dimension of the MIMO system is only $15.5 \times 18 \mathrm{~mm}^{2}$, less than $12.8 \%$ of the size reported in [17]. A measured operating band of $310 \mathrm{MHz}(2.20-2.51 \mathrm{GHz})$ is obtained to cover the LTE $2300 / \mathrm{ISM} 2.45 \mathrm{GHz}$ operation. Isolation higher than $16 \mathrm{~dB}$ can be achieved with a small edge-to-edge separation of $2.6 \mathrm{~mm}(0.02 \lambda)$. The correlation coefficients between the two elements are well less than 0.3 and total efficiencies are larger than $78 \%$, which made this MIMO antenna system competitive for mobile MIMO terminal designs. 


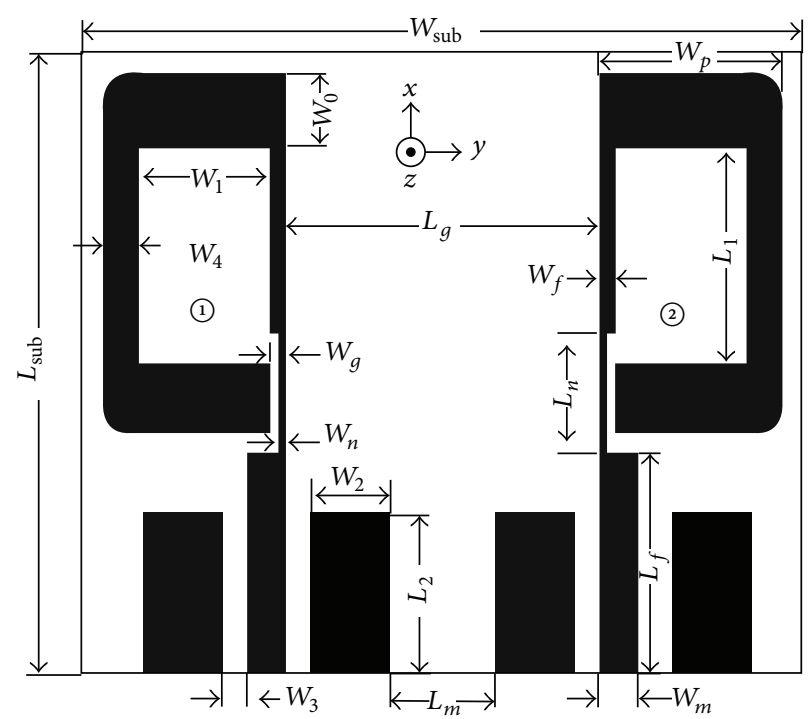

FIgURE 1: Proposed antenna configuration.

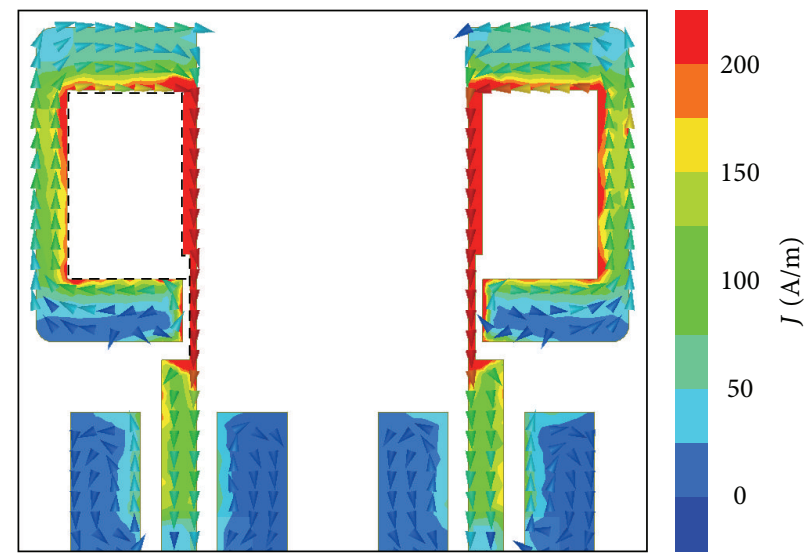

FIGURE 2: Surface current distribution when both elements are excited at $2.45 \mathrm{GHz}$.

\section{MIMO Antenna Design}

2.1. Proposed Antenna Configuration. Figure 1 shows the geometry of the proposed dual-element MIMO antenna for LTE/ISM operation. In this paper, the presented antenna system is formed by two symmetric planar monopole antennas and is printed on a $1.6 \mathrm{~mm}$ thick FR4 substrate of relative permittivity 4.4 and loss tangent 0.02 . The detailed dimensions of the proposed MIMO antenna system are as follows: $L_{\text {sub }}=15.5 \mathrm{~mm}, W_{\text {sub }}=18 \mathrm{~mm}, W_{0}=1.8 \mathrm{~mm}$, $W_{1}=3.3 \mathrm{~mm}, W_{2}=2 \mathrm{~mm}, W_{3}=0.6 \mathrm{~mm}, W_{4}=0.9 \mathrm{~mm}$, $W_{f}=0.4 \mathrm{~mm}, W_{g}=0.2 \mathrm{~mm}, W_{m}=1 \mathrm{~mm}, W_{n}=0.2 \mathrm{~mm}$, $W_{p}=4.6 \mathrm{~mm}, L_{1}=5.4 \mathrm{~mm}, L_{2}=4 \mathrm{~mm}, L_{f}=5.5 \mathrm{~mm}$, $l_{g}=7.8 \mathrm{~mm}, L_{m}=2.6 \mathrm{~mm}$, and $L_{n}=3 \mathrm{~mm}$.

2.2. Design Procedure. The limitation of space becomes the most challenging task in designing antennas for modern wireless devices. Meanwhile, electrically small antenna always faces a narrow bandwidth problem. Planar monopole antenna has attractive characteristics such as simple structure, omnidirectional radiation pattern, low profile, and wide bandwidth, which made it a competitive candidate for MIMO antenna systems.

In this paper, the radiation patch and ground of the antenna are on the same side of the substrate. In order to design the antenna to resonate at the desired frequency, we use the following two equations in parameters optimization:

$$
\lambda=\frac{c}{\sqrt{\varepsilon_{\text {eff }}} f}
$$

with

$$
\varepsilon_{\mathrm{eff}}=\frac{\varepsilon_{r}+1}{2}
$$

In Figure 2, both elements are excited and when $W_{g}=$ $0.2 \mathrm{~mm}$, the resonant frequency is $2.45 \mathrm{GHz}$ and the length 


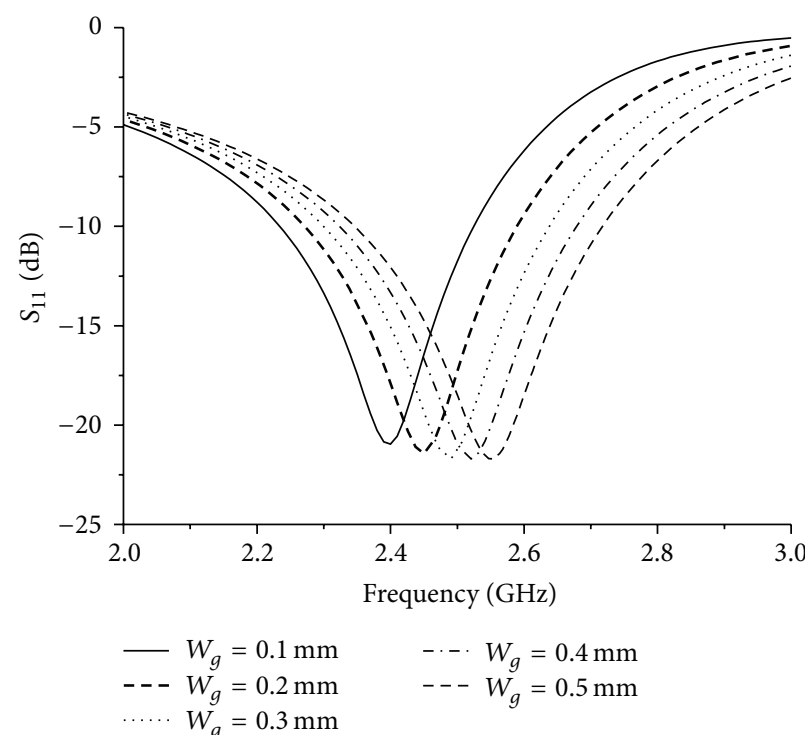

(a)

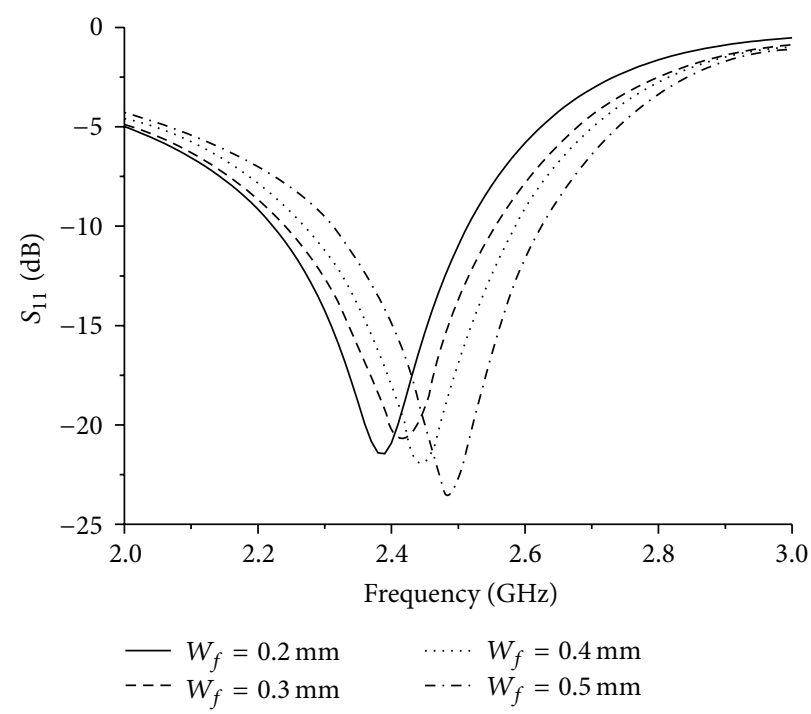

(b)

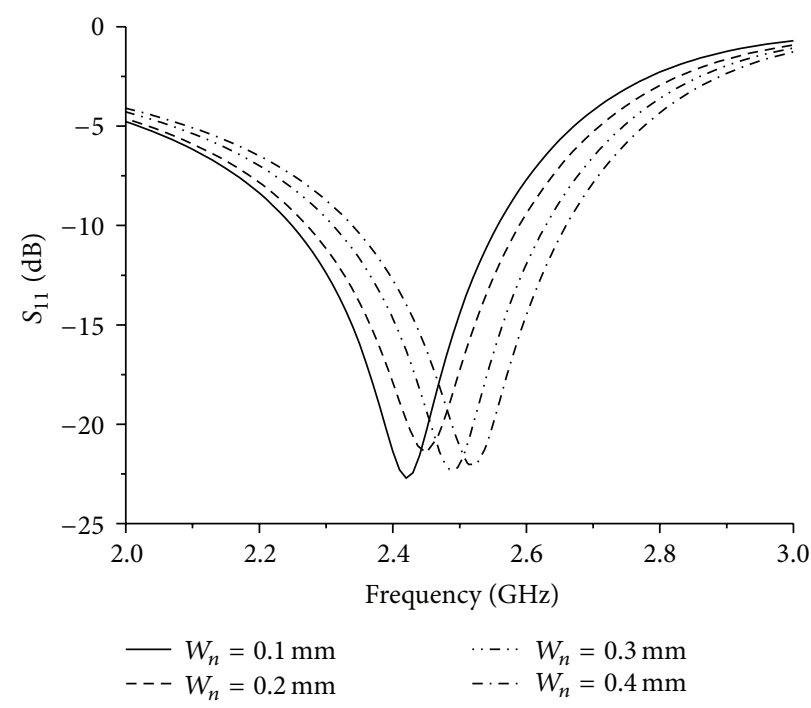

(c)

FIGURE 3: Simulated reflection coefficients as a function of (a) $W_{g}$, (b) $W_{f}$, and (c) $W_{n}$.

of the surface current path (the dot line in Figure 2) at this frequency is $18.6 \mathrm{~mm}$, which is one-quarter of the wavelength calculated by (1). When $W_{g}=0.4 \mathrm{~mm}$, the resonant frequency shifts to $2.53 \mathrm{GHz}$, and the length of the surface current path changed to $18.0 \mathrm{~mm}$, which is just one-fourth of the wavelength at this frequency. The changes of $W_{n}$ and $W_{f}$ have similar effect on the antenna resonance. Figure 3 shows the relationship between the width of $W_{g}, W_{n}$, and $W_{f}$ and the reflection coefficients.

Figure 4 is the surface current when only element number 1 is excited at $2.45 \mathrm{GHz}$. Because of the high isolation between antenna elements, little coupling current is on the other element. Compared to the current rotation in Figure 2, the direction of the coupling current on element number 2 in
Figure 4 is opposite with the excited current on element number 2 in Figure 2.

Two types of dual-element antenna arrays are demonstrated in Figures 5(a) and 6(a). The two elements are no longer symmetrical but are in the same direction. For Type I, the edge-to-edge separation of the ground is the same with the proposed one; considering the shape of the radiation patch, the distance between the two elements is decreased and the isolation deteriorated, shown in Figure 5(b).

For Type II, the space between the two radiation patches is kept the same with the proposed one; the actual distance between the antenna elements is increased, but the isolation is still lower than the proposed MIMO antenna 


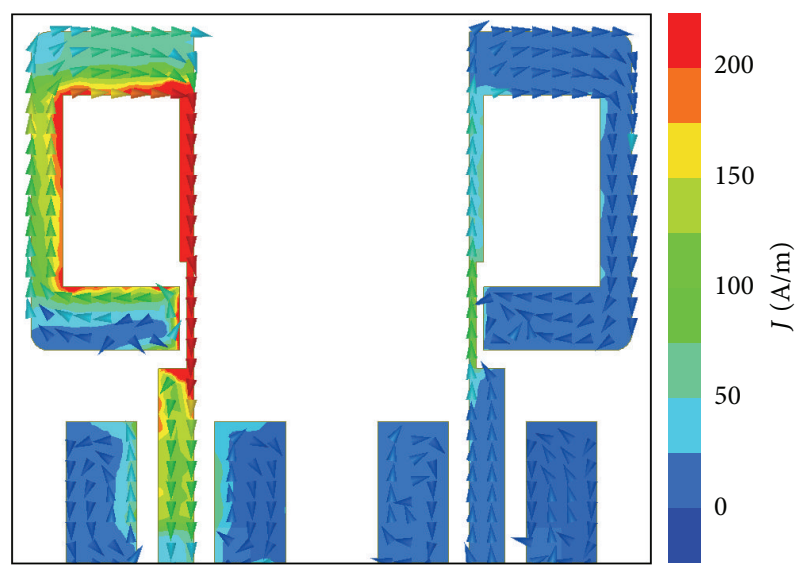

FIgURE 4: Surface current distribution when only one element is excited at $2.45 \mathrm{GHz}$.

system. So the isolation is affected not only by the distance between elements, but also by the rotation of the currents on the radiation patch. Due to the well known skin effect, the two elements can be seen acting like two loop antennas at the operating band. So when only one antenna is excited, the coupled current on the other element has the same rotation or polarization with the exited one (Figure 4); while two elements are excited simultaneously, the rotation or the polarization is just opposite (Figure 2); this to some extent reduced the coupling between the elements.

The two antenna elements can also be orthogonally placed as shown in Figure 7(a). Compared to the proposed MIMO antenna system, the isolation is $1-2 \mathrm{~dB}$ higher due to the arrangement of the antenna element. However, the size of the total system is larger than the proposed one. So the final choice is a compromise between space and system performance.

\section{Results and Discussion}

3.1. Measured Results. Figure 8 shows the photograph of the fabricated antenna. The antenna elements are fed by $50 \Omega$ MCX connectors [18].

The simulated and measured $S$ parameters of the MIMO antenna system are shown in Figure 9. The simulated results were achieved by Ansoft HFSS version 15, while the measured results were obtained by using Agilent $85058 \mathrm{E}$ vector network analyzer. The simulated bandwidth was $320 \mathrm{MHz}$ $(2.26-2.58 \mathrm{GHz})$, the simulated $S_{11}$ curve coincides with the simulated $S_{22}$ curve, and the measured bandwidth was $310 \mathrm{MHz}(2.20-2.51 \mathrm{GHz})$. The difference between them was probably due to the fabricated imperfections and the loss of the feeding cable and connectors. The measured $-10 \mathrm{~dB}$ impedance bandwidth can cover the desired LTE 2300 and $2.45 \mathrm{GHz}$ ISM band.

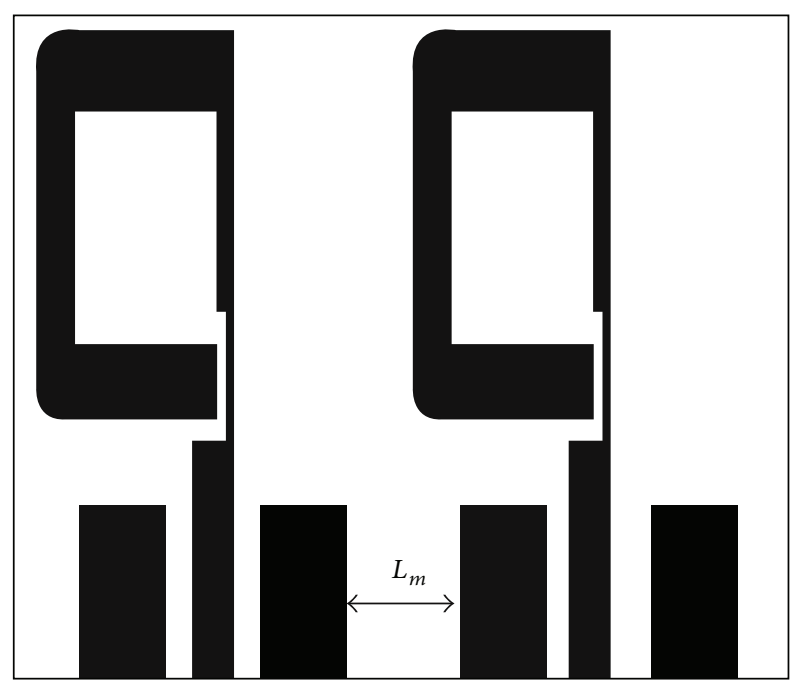

Size $18 \mathrm{~mm} \times 15.5 \mathrm{~mm}$

(a)

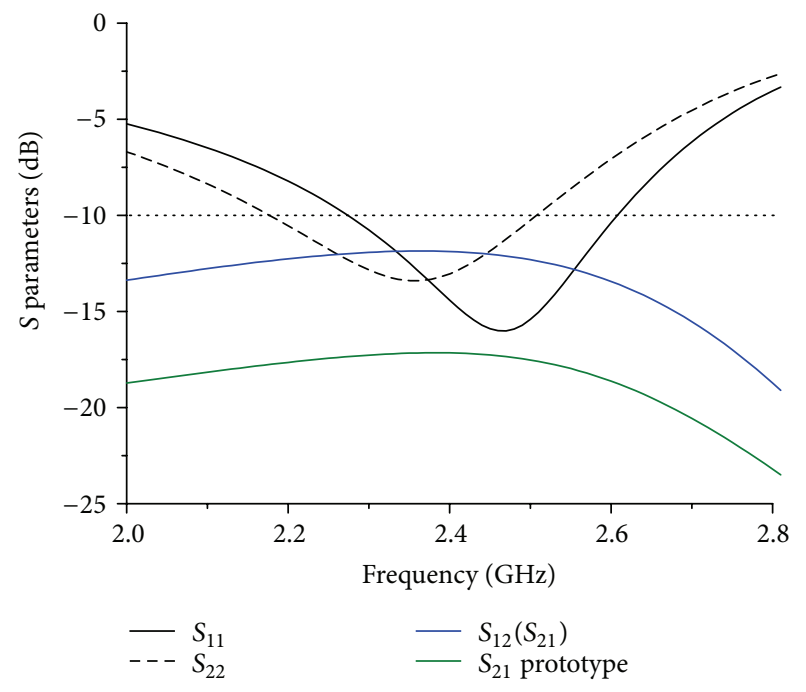

(b)

Figure 5: (a) MIMO antenna system Type I, (b) $S$ parameters of Type I.

Figure 10 shows the isolation between antenna elements. Through the whole operating band, the isolation is higher than $16 \mathrm{~dB}$.

The correlation coefficient $(\rho)$ is an important parameter to evaluate the diversity performance of the multiantenna systems. The lower $\rho$ results in better MIMO system performance. It is usually calculated from $3 \mathrm{D}$ radiation patterns. However, this procedure is rather complicate; recent research indicates that the correlation coefficient can be easily derived from the $S$-parameters [19] with the following expression:

$$
\left|\rho_{i j}\right|=\frac{\left|S_{i i}{ }^{*} S_{i j}+S_{i j}{ }^{*} S_{j j}\right|}{\sqrt{\left|\left(1-\left|S_{i i}{ }^{2}\right|-\left|S_{j i}{ }^{2}\right|\right)\left(1-\left|S_{j j}{ }^{2}\right|-\left|S_{i j}{ }^{2}\right|\right) \eta_{i} \eta_{j}\right|}} .
$$




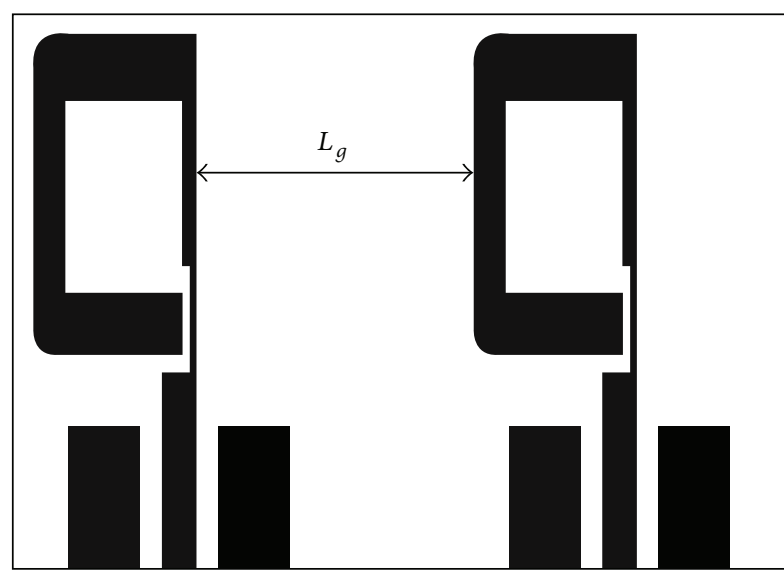

Size $21.6 \mathrm{~mm} \times 15.5 \mathrm{~mm}$

(a)

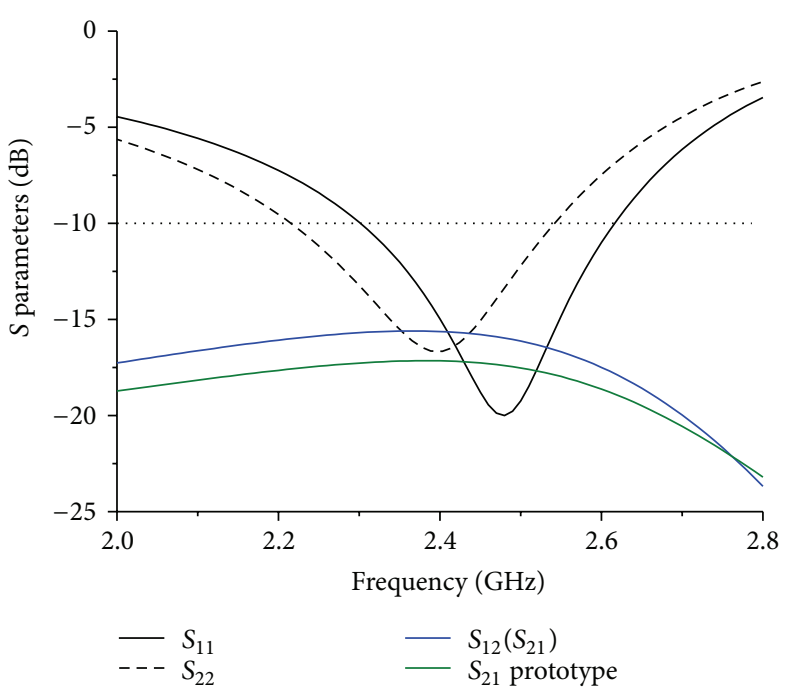

(b)

Figure 6: (a) MIMO antenna system Type II, (b) $S$ parameters of Type II.

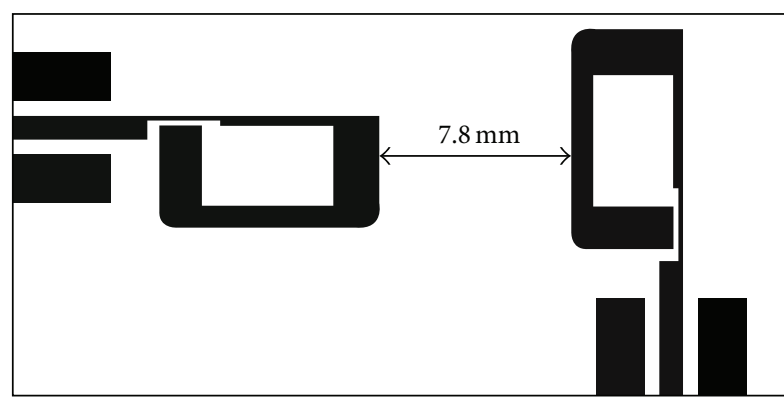

Size $31.5 \mathrm{~mm} \times 15.5 \mathrm{~mm}$

(a)

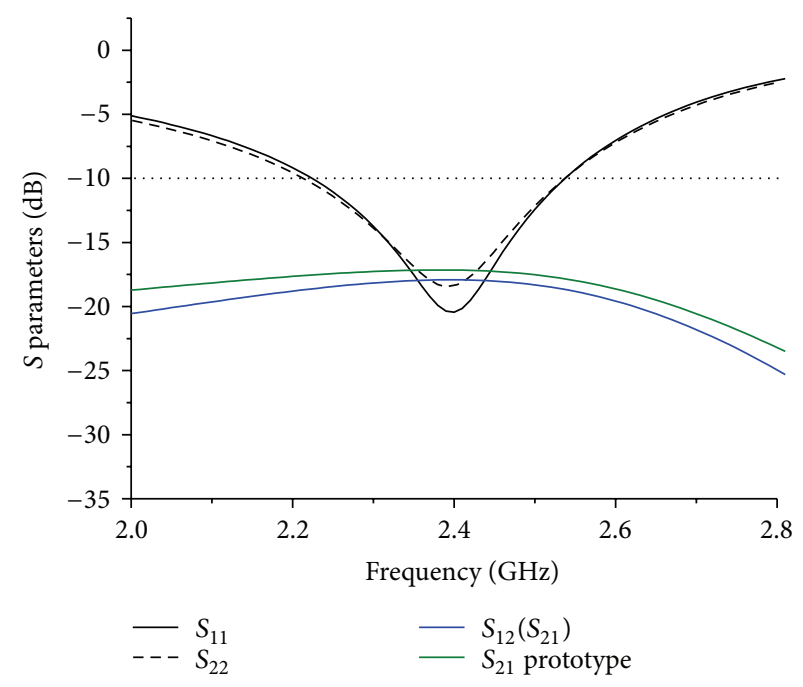

(b)

Figure 7: (a) Orthogonally arranged MIMO antenna system, (b) $S$ parameters.

Figure 11 shows the correlation coefficient between the antenna elements of the proposed MIMO antenna system. The antenna efficiency was higher than $78 \%$ through the working band. The results are well below 0.3 , which is the maximum value set for $4 \mathrm{G}$ standards [20].

The gain of the proposed MIMO antenna system is shown in Figure 12. The simulated peak gain in the $+z$ direction is $0.72 \mathrm{dBi}$ at $2.41 \mathrm{GHz}$ and the measured peak gain is $0.62 \mathrm{dBi}$ at $2.4 \mathrm{GHz}$.

The radiation pattern of the proposed MIMO antenna system is shown in Figure 13. The radiation pattern was obtained when one element was excited and the other is terminated with a $50 \mathrm{ohm}$ load. The radiation pattern is just like a monopole, which has an omnidirectional radiation in the $H$ plane at the resonant frequency.

3.2. Eight-Element MIMO Systems. According to [21], the increase of the number of transmitter antennas and receiver antennas can improve the communication quality and increase the channel capacity without extra radiation power and spectrum bandwidth. An eight-element MIMO antenna system was also fabricated and measured. Its measured 


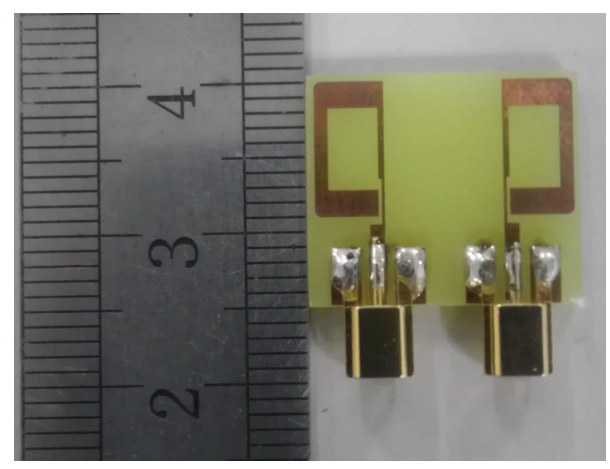

FIGURE 8: Photograph of the fabricated MIMO antenna system.

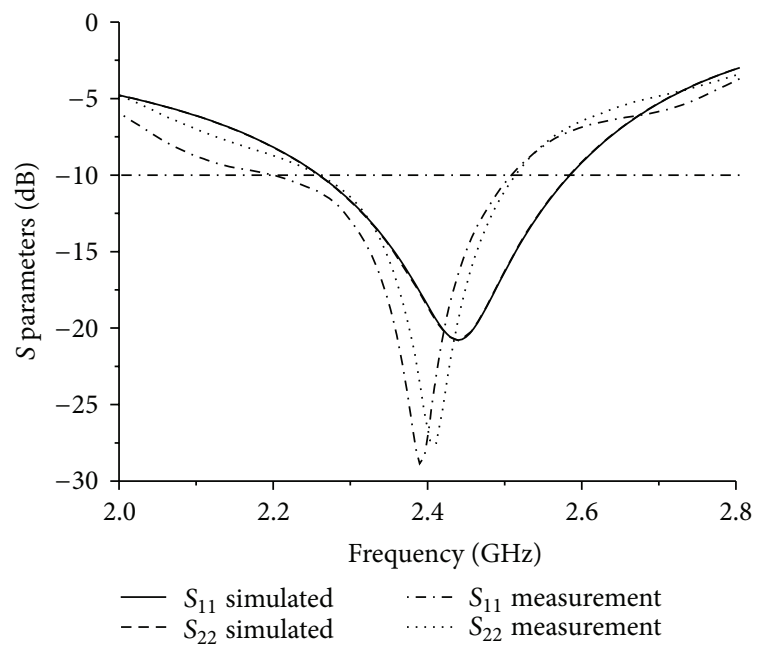

FIGURE 9: Simulated and measured $S$ parameters of the proposed MIMO antenna system.

$-10 \mathrm{~dB}$ bandwidth is $340 \mathrm{MHz}(2.18-2.52 \mathrm{GHz})$, as shown in Figure 14(a); good agreement is realized; for the sake of clarity, we only put the results of four antennas here. The measured isolation between antennas is lower than $-15 \mathrm{~dB}$ at the whole operating band. The simulated radiation efficiency of the antenna element is higher than $77 \%$ over the whole band. The correlation coefficient can be calculated by using (3). As plotted in Figure 14(d), the value is far smaller than 0.3 .

3.3. Practical Applications. For practical applications, MIMO antenna system is integrated with other components such as circuit board and LCD screen, which means that a conductive plane under the system should be taken into consideration.

In Figure 15(a), the MIMO antenna system was placed above a metal sheet separated by free space. The separation between the conductive board and antenna bottom side was varied from 1 to $5 \mathrm{~mm}$ in 1-mm steps. Figures 15(b) and 15 (c) show the reflection coefficients and the isolation characteristics of the antenna element over a metal sheet at different distances.

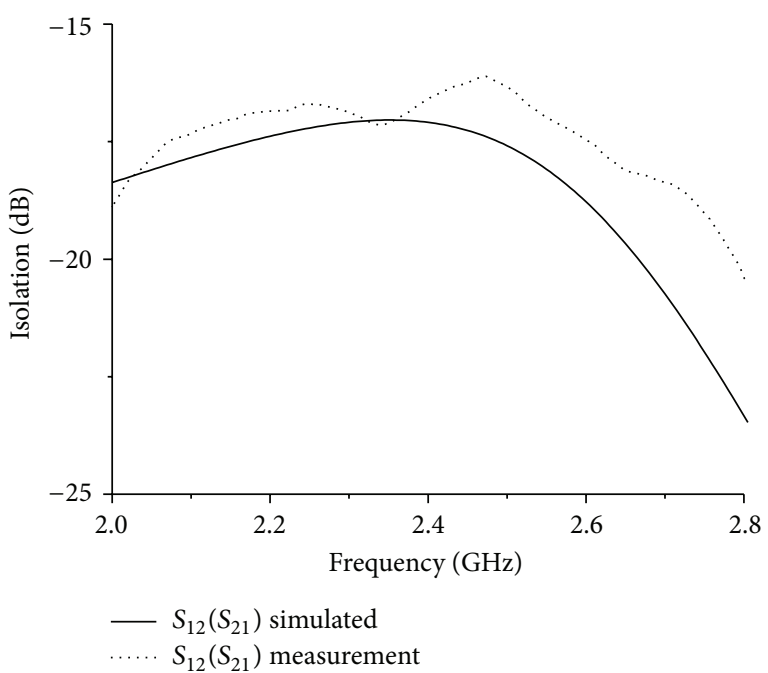

FIGURE 10: Isolation of MIMO antenna system.

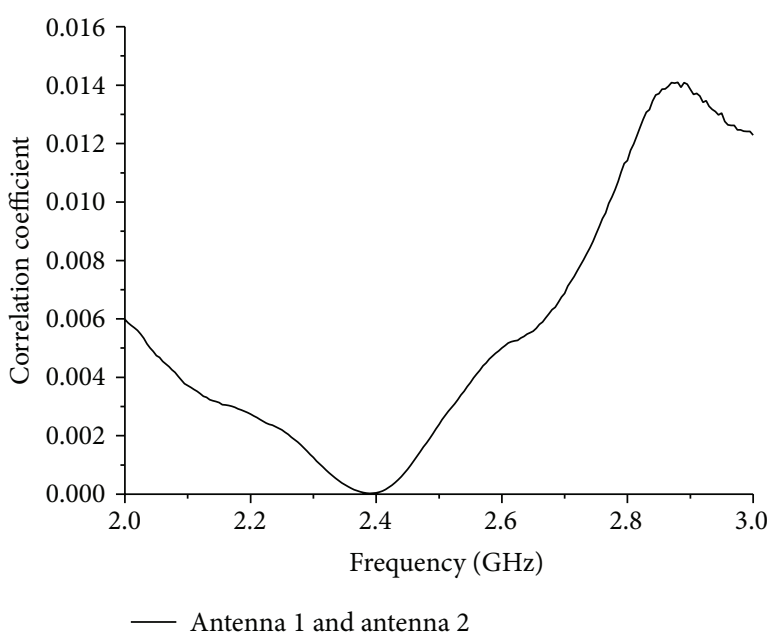

FIGURE 11: Correlation coefficient curve for the proposed MIMO antenna system.

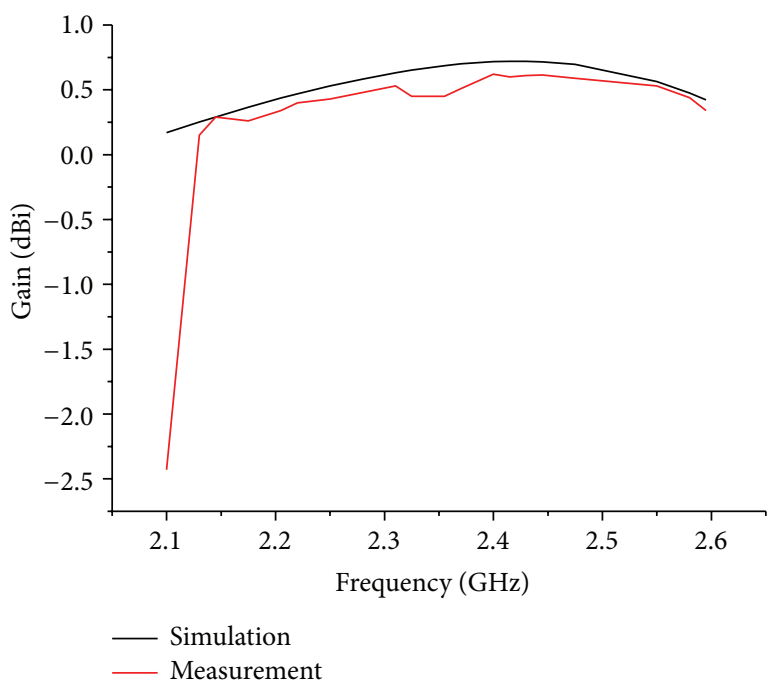

FIGURE 12: Gain of MIMO antenna system. 

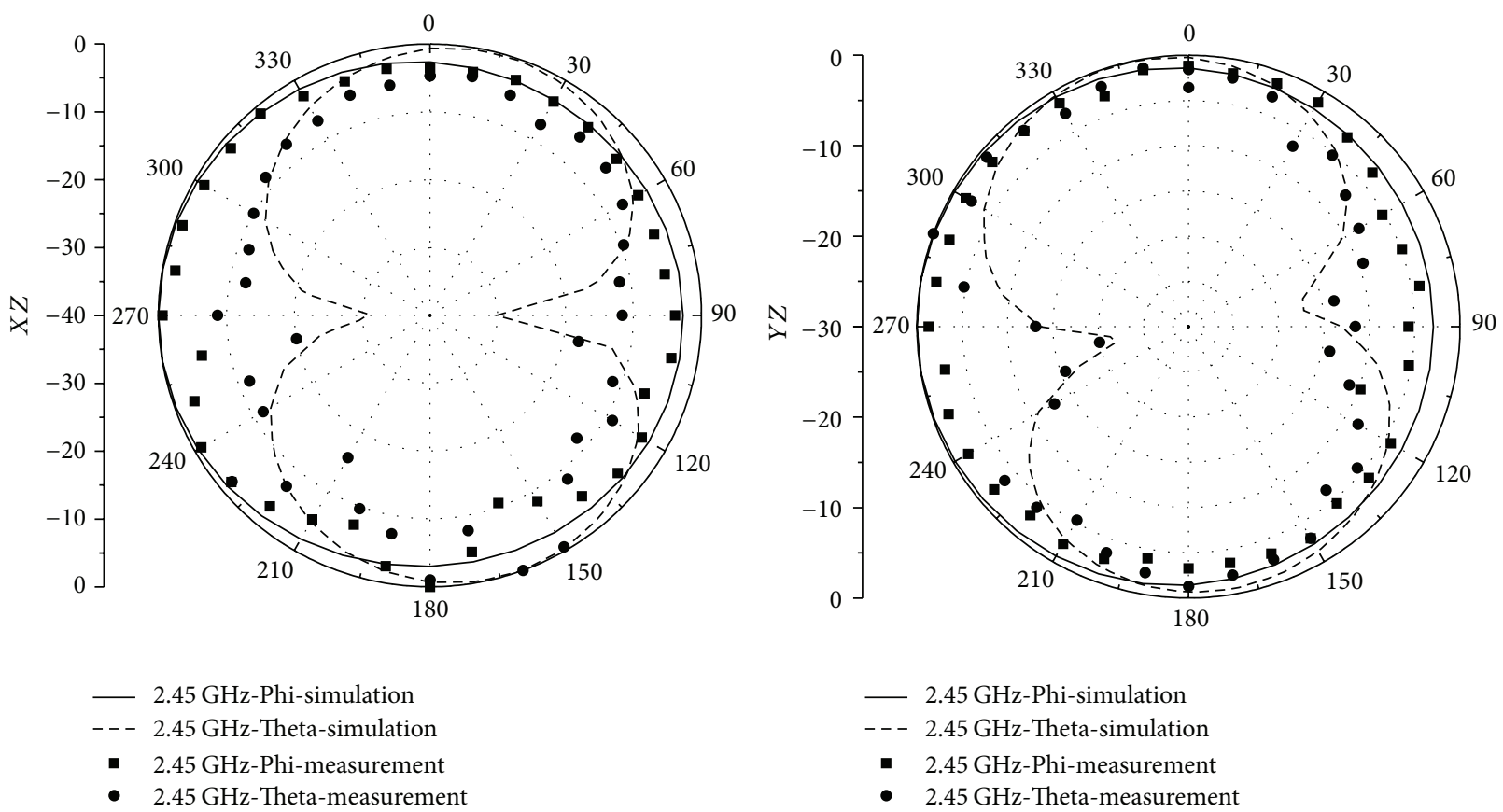

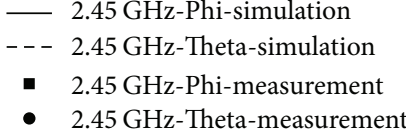

(a)

(b)

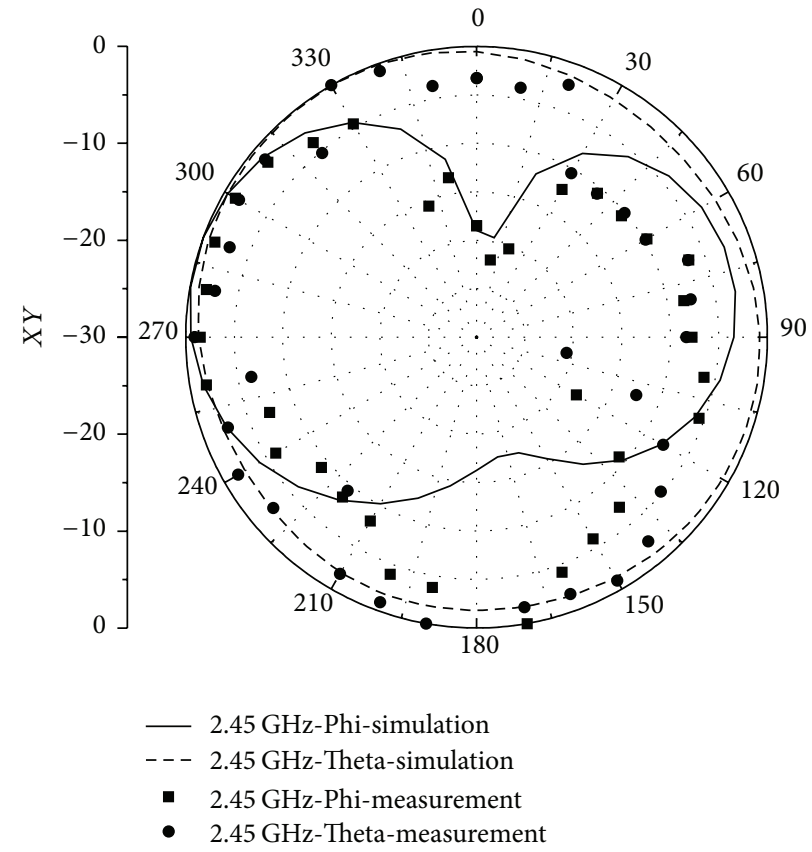

(c)

FIGURE 13: Radiation pattern of the proposed MIMO antenna at $2.45 \mathrm{GHz}$. (a) $x z$-plane, (b) $y z$-plane, and (c) $x y$-plane.

It was found that, by using a metal sheet, the resonant frequency of the individual antenna element shifted. As the distance between the antenna and conductive plane increased, the effect weakens. When the board is closely placed under the system like $1 \mathrm{~mm}$, the resonant frequency changed most, but the working band can still cover the LTE2300 and $2.45 \mathrm{GHz}$ ISM band. This is unlike the system reported in [22]; the antenna system does not have any special designed structures on the back side of the substrate, so it is not obligatory to place the system carefully such that its bottom side maintains a minimum distance like 3 to $5 \mathrm{~mm}$ from any conductive plane for practical design.

Figure 16 (a) shows a $1 \mathrm{~mm}$ thick plastic housing which is used to simulate the practical case of the wireless terminals. In simulation, the relative permittivity of the plastic housing is 


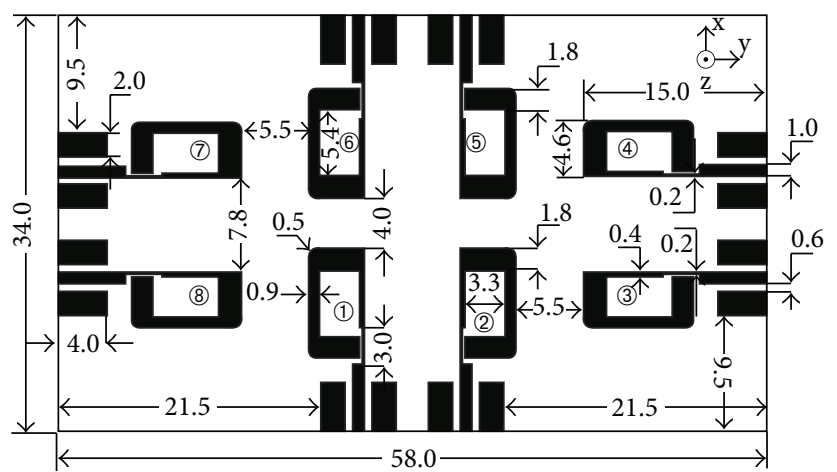

(a)

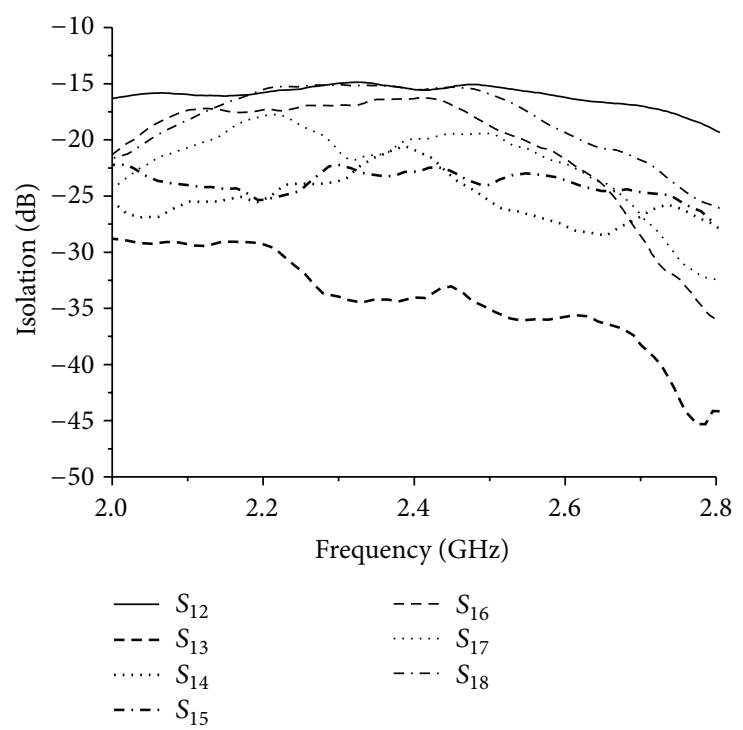

(c)

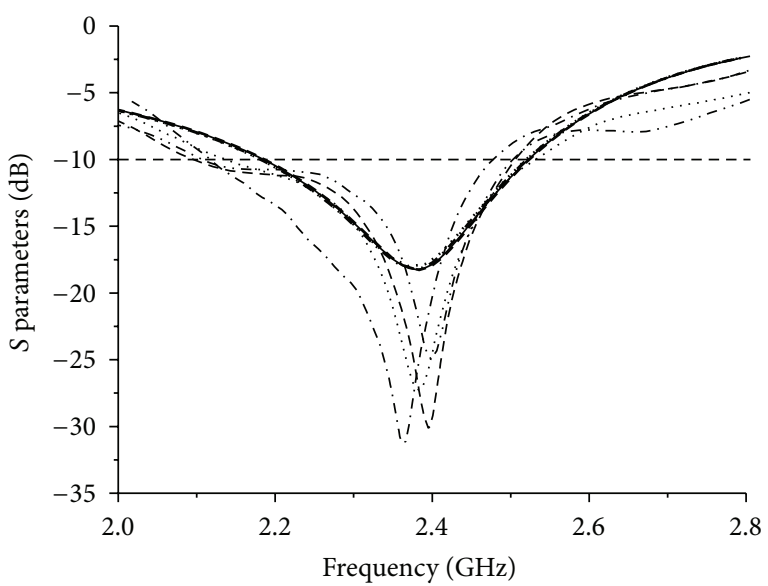

- $S_{11}$ simulation

- - $S_{22}$ simulation

…. $S_{33}$ simulation

-.- $S_{44}$ simulation

(b)

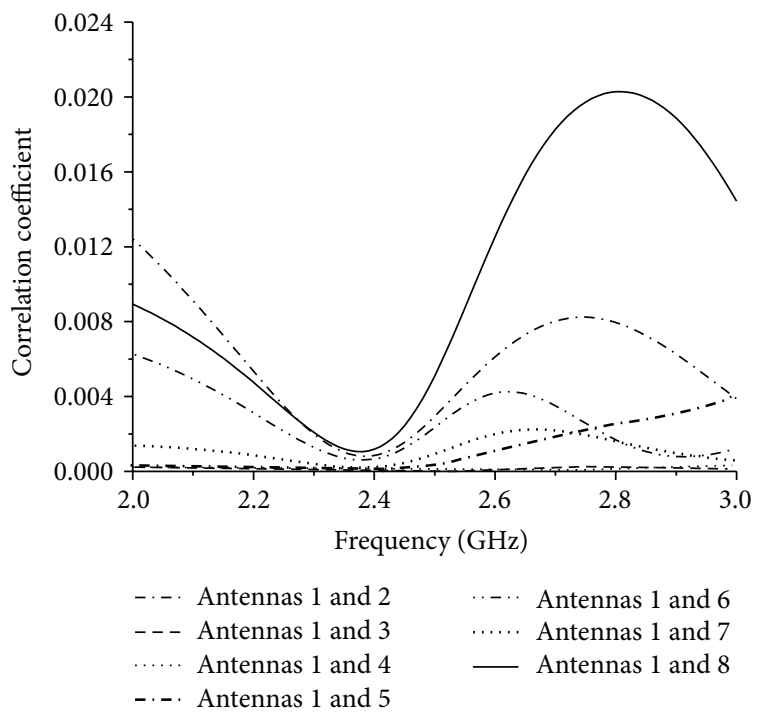

(d)

FIGURE 14: (a) Geometry of the 8-element MIMO antenna system. (b) Reflection coefficients of the MIMO antenna system. (c) Measured isolation between MIMO antenna elements. (d) Correlation coefficient $|\rho|$ curves for the proposed MIMO antenna system.

set as 3.3 and the loss tangent is 0.02 , the same as [23]. Figures $16(\mathrm{~b})$ and 16 (c) show the influence of the plastic housing on reflection coefficients and isolation. Differences between the two cases are small and acceptable and show this MIMO system is competitive for practical application.

\section{Conclusion}

Symmetric planar monopole antenna for compact multielement MIMO antenna systems is proposed. Isolation higher than $15 \mathrm{~dB}$ over the operating band is realized by using polarization diversity of the antenna elements. Correlation coefficient, $S$-parameters, radiation characteristics, and acceptable performance when placed with conductive plane and plastic housing show that the proposed antenna arrays can be used for practical MIMO applications.

\section{Conflict of Interests}

The authors declare that there is no conflict of interests regarding the publication of this paper. 


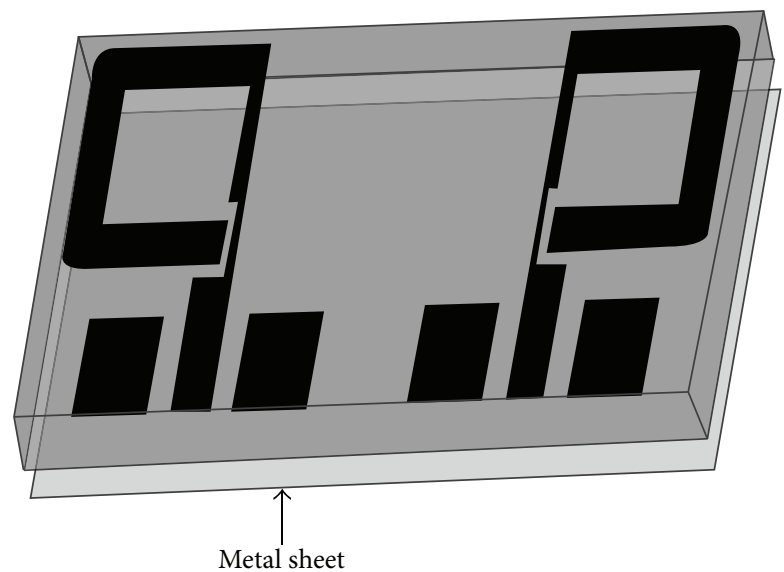

(a)

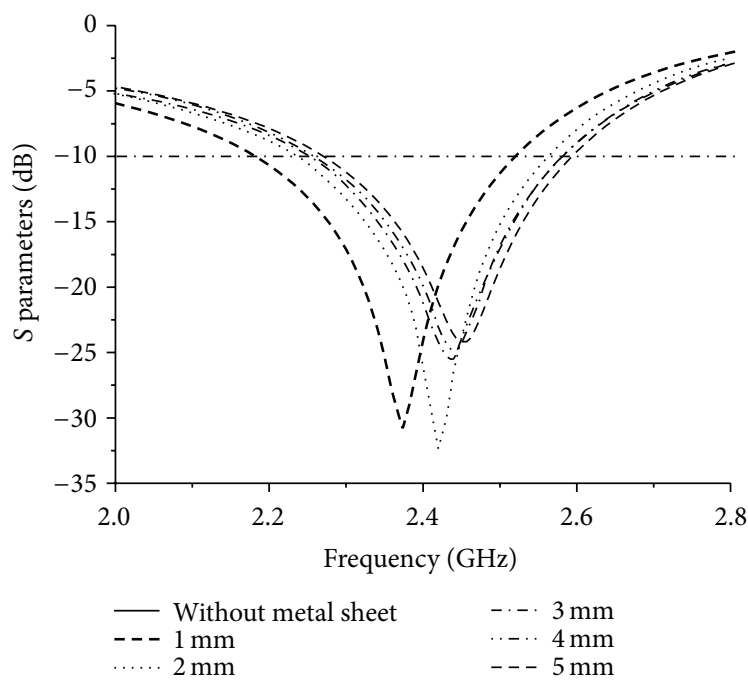

(b)

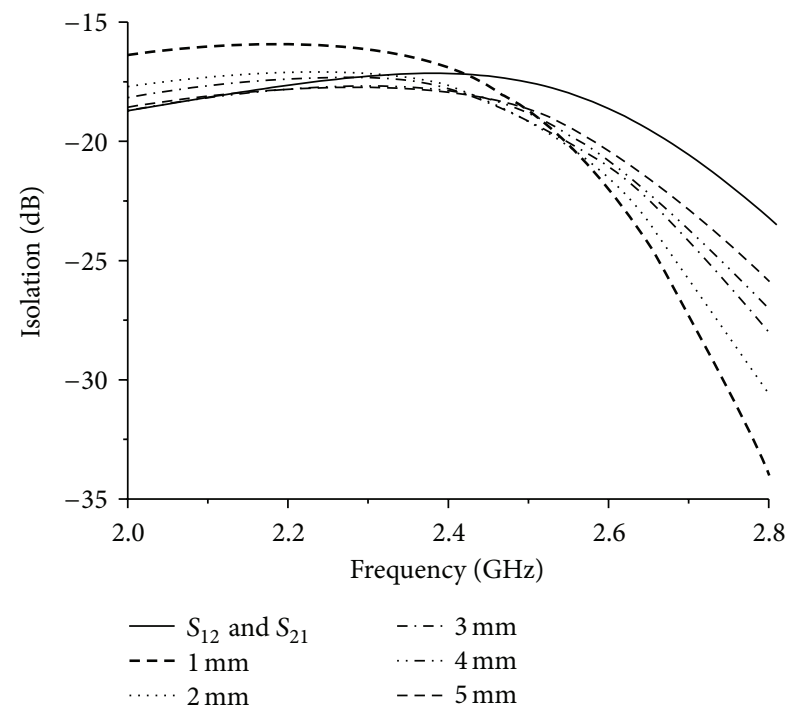

(c)

FIGURE 15: (a) Proposed MIMO antenna with a metal sheet separated by free space. (b) Reflection coefficients of the MIMO antenna system with a metal sheet. (c) Isolation of the MIMO antenna system with a metal sheet.

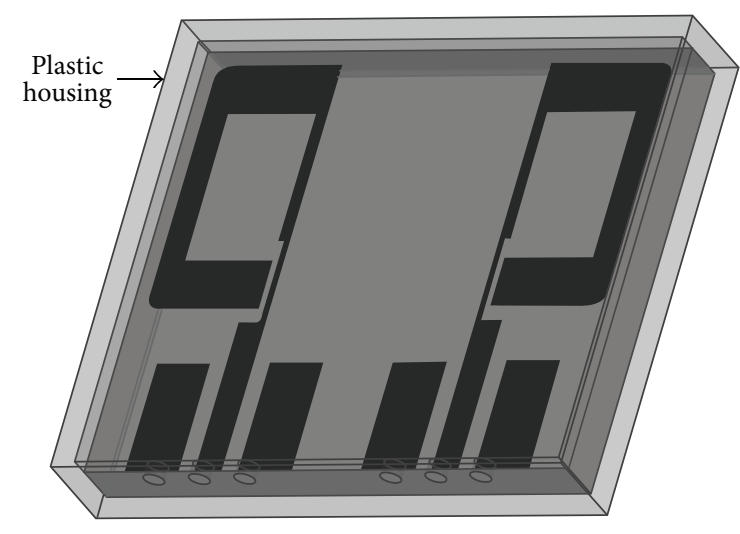

(a)

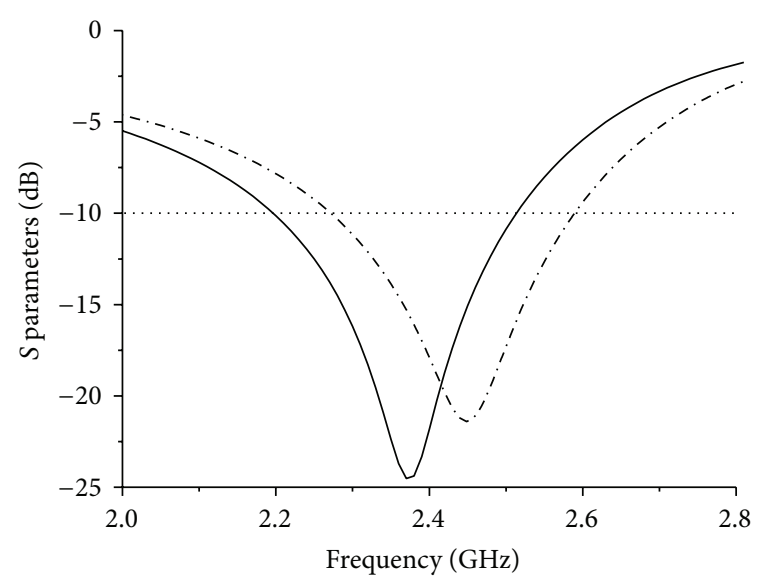

- $S_{11}$ with plastic housing

-.. $S_{11}$ without plastic housing

(b)

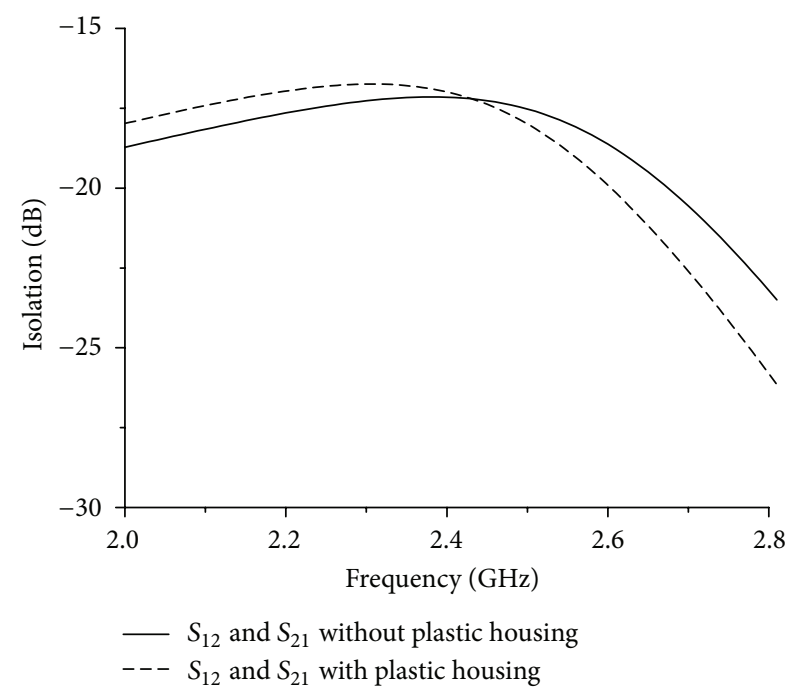

(c)

FIGURE 16: (a) Proposed antenna with plastic housing. (b) Reflection coefficients. (c) Isolation. 


\section{Acknowledgment}

This work was supported by the Priority Academic Program Development of Jiangsu Higher Education Institutions (PAPD).

\section{References}

[1] T. Kokkinos, E. Liakou, and A. P. Feresidis, "Decoupling antenna elements of PIFA arrays on handheld devices," Electronics Letters, vol. 44, no. 25, pp. 1442-1444, 2008.

[2] H. Li, J. Xiong, Z. Ying, and S. L. He, "Compact and low profile co-located MIMO antenna structure with polarisation diversity and high port isolation," Electronics Letters, vol. 46, no. 2, pp. 108-110, 2010.

[3] S. Zhang, P. Zetterberg, and S. He, "Printed MIMO antenna system of four closely-spaced elements with large bandwidth and high isolation," Electronics Letters, vol. 46, no. 15, pp. 10521053, 2010.

[4] C. Yang, J. Kim, H. Kim, J. Wee, B. Kim, and C. Jung, "Quadband antenna with high isolation MIMO and broadband SCS for broadcasting and telecommunication services," IEEE Antennas and Wireless Propagation Letters, vol. 9, pp. 584-587, 2010.

[5] S. Park and C. Jung, "Compact MIMO antenna with high isolation performance," Electronics Letters, vol. 46, no. 6, pp. 390-391, 2010.

[6] H. S. Farahani, M. Veysi, M. Kamyab, and A. Tadjalli, "Mutual coupling reduction in patch antenna arrays using a UC-EBG superstrate," IEEE Antennas and Wireless Propagation Letters, vol. 9, pp. 57-59, 2010.

[7] G. Expósito-Domínguez, J. M. Fernández-González, P. Padilla, and M. Sierra-Castaner, "New EBG solutions for mutual coupling reduction," in Proceedings of the 6th European Conference on Antennas and Propagation (EUCAP '12), pp. 2841-2844, IEEE, Prague, Czech Republic, March 2012.

[8] A. Habashi, J. Nourinia, and C. Ghobadi, "A rectangular defected ground structure (DGS) for reduction of mutual coupling between closely-spaced microstrip antennas," in Proceedings of the 20th Iranian Conference on Electrical Engineering (ICEE '12), pp. 1347-1350, IEEE, Tehran, Iran, May 2012.

[9] L. Wang and B. Huang, "Design of ultra-wideband MIMO antenna for breast tumor detection," International Journal of Antennas and Propagation, vol. 2012, Article ID 180158, 7 pages, 2012.

[10] M. Gallo, E. Antonino-Daviu, M. Ferrando-Bataller, M. Bozzetti, J. M. Molina-Garcia-Pardo, and L. Juan-Llacer, "A broadband pattern diversity annular slot antenna," IEEE Transactions on Antennas and Propagation, vol. 60, no. 3, pp. 15961600, 2012.

[11] D.-G. Kang, J. Tak, and J. Chio, "MIMO antenna with high isolation for WBAN applications," International Journal of Antennas and Propagation, vol. 2015, Article ID 370763, 7 pages, 2015.

[12] Y. K. Choukiker, S. K. Sharma, and S. K. Behera, "Hybrid fractal shape planar monopole antenna covering multiband wireless communications with MIMO implementation for handheld mobile devices," IEEE Transactions on Antennas and Propagation, vol. 62, no. 3, pp. 1483-1488, 2014.

[13] Q. Zeng, Y. Yao, S. Liu, J. Yu, P. Xie, and X. Chen, “Tetraband small-size printed strip MIMO antenna for mobile handset application," International Journal of Antennas and Propagation, vol. 2012, Article ID 320582, 8 pages, 2012.

[14] K. Wang, R. A. M. Mauermayer, and T. F. Eibert, "Compact twoelement printed monopole array with partially extended ground plane," IEEE Antennas and Wireless Propagation Letters, vol. 13, pp. 138-140, 2014.

[15] J. Park, J. Choi, J.-Y. Park, and Y.-S. Kim, "Study of a Tshaped slot with a capacitor for high isolation between MIMO antennas," IEEE Antennas and Wireless Propagation Letters, vol. 11, pp. 1541-1544, 2012.

[16] M. G. N. Alsath, M. Kanagasabai, and B. Balasubramanian, "Implementation of slotted meander-line resonators for isolation enhancement in microstrip patch antenna arrays," IEEE Antennas and Wireless Propagation Letters, vol. 12, pp. 15-18, 2013.

[17] H. Arun, A. K. Sarma, M. Kanagasabai, S. Velan, C. Raviteja, and M. G. N. Alsath, "Deployment of modified serpentine structure for mutual coupling reduction in MIMO antennas," IEEE Antennas and Wireless Propagation Letters, vol. 13, pp. 277280, 2014.

[18] https://en.wikipedia.org/wiki/MCX_connector.

[19] S. Blanch, J. Romeu, and I. Corbella, "Exact representation of antenna system diversity performance from input parameter description," Electronics Letters, vol. 39, no. 9, pp. 705-707, 2003.

[20] 3GPP, "EUTRA user equipment radio transmission and reception," 3GPP TS 36.101, V8.3.0, September 2008.

[21] L. Song and J. Shen, Evolved Cellular Network Planning and Optimization for UMTS and LTE, CRC Press, London, UK, 2011.

[22] M. S. Sharawi, M. U. Khan, A. B. Numan, and D. N. Aloi, "A CSRR loaded MIMO antenna system for ISM band operation," IEEE Transactions on Antennas and Propagation, vol. 61, no. 8, pp. 4265-4274, 2013.

[23] Y.-L. Ban, J.-H. Chen, J. L.-W. Li, and Y. J. Wu, "Small-size printed coupled-fed antenna for eight-band LTE/GSM/UMTS wireless wide area network operation in an internal mobile handset," IET Microwaves, Antennas \& Propagation, vol. 7, no. 6, pp. 399-407, 2013. 

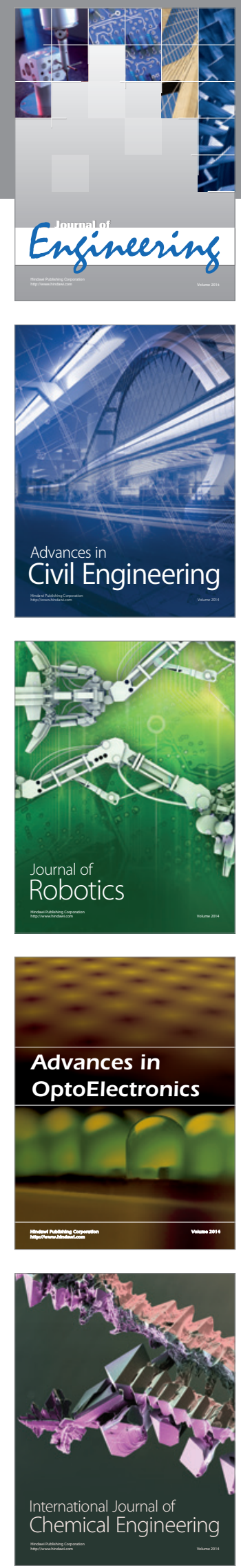

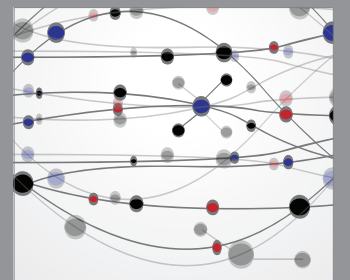

The Scientific World Journal
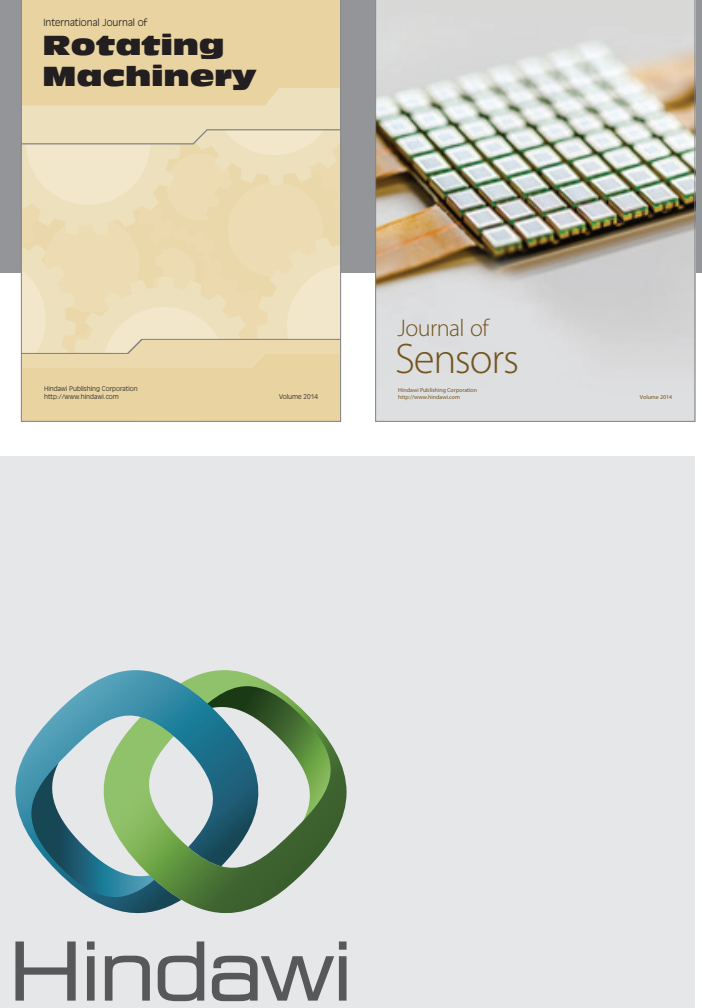

Submit your manuscripts at http://www.hindawi.com
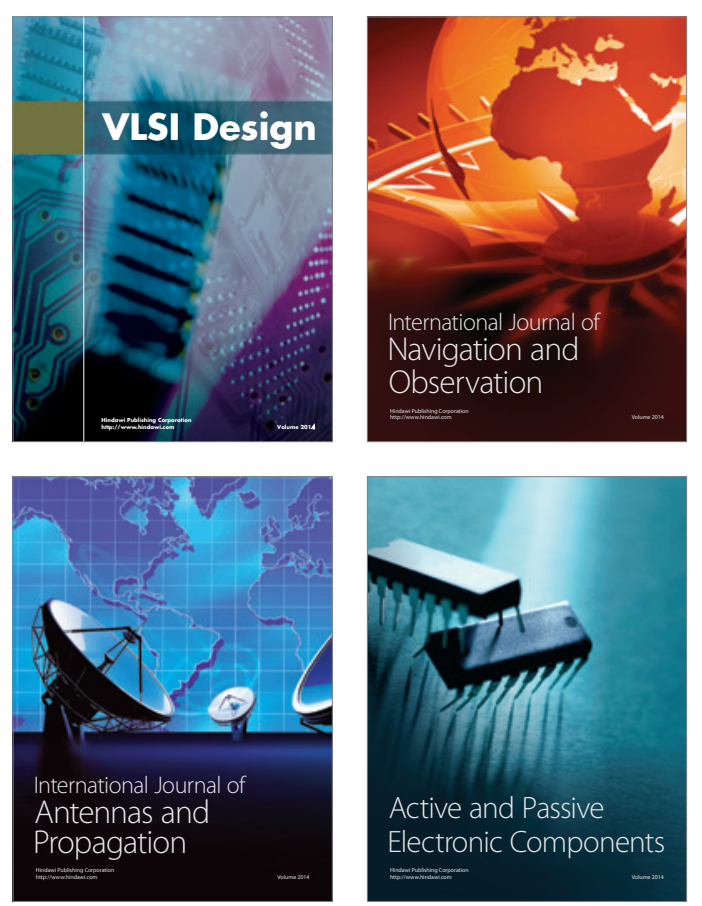
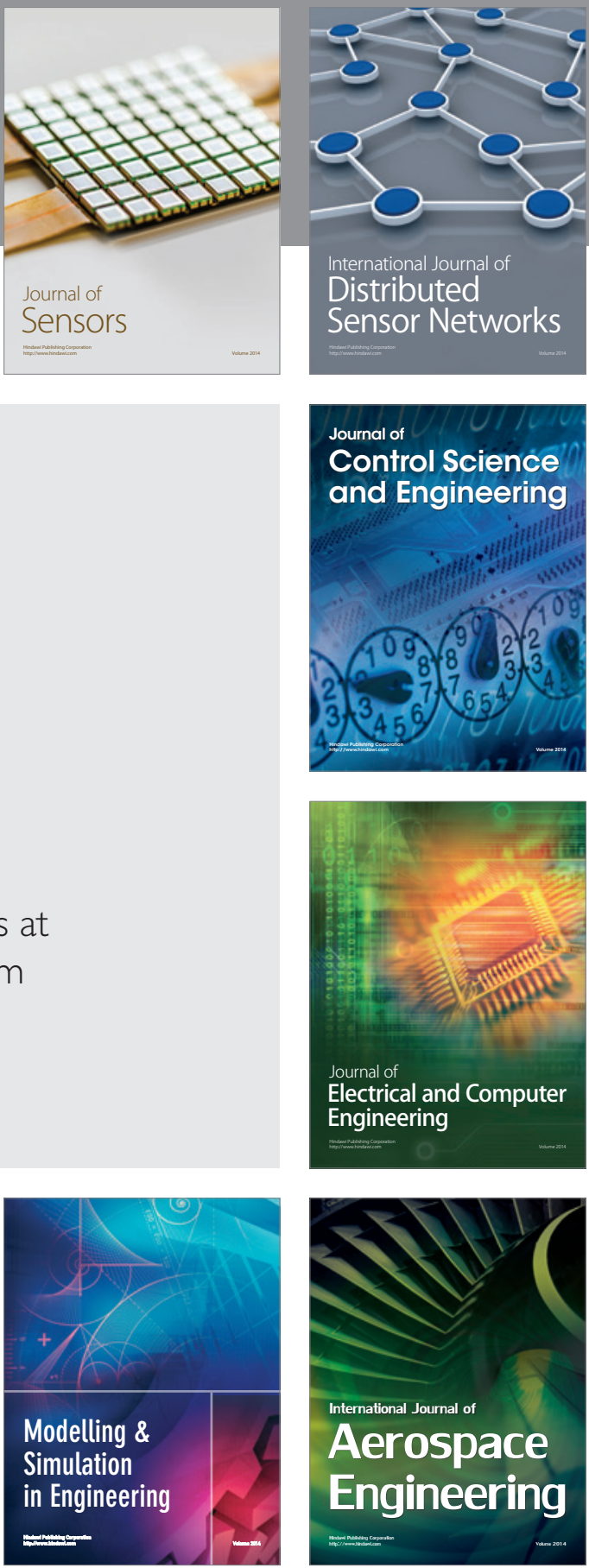

Journal of

Control Science

and Engineering
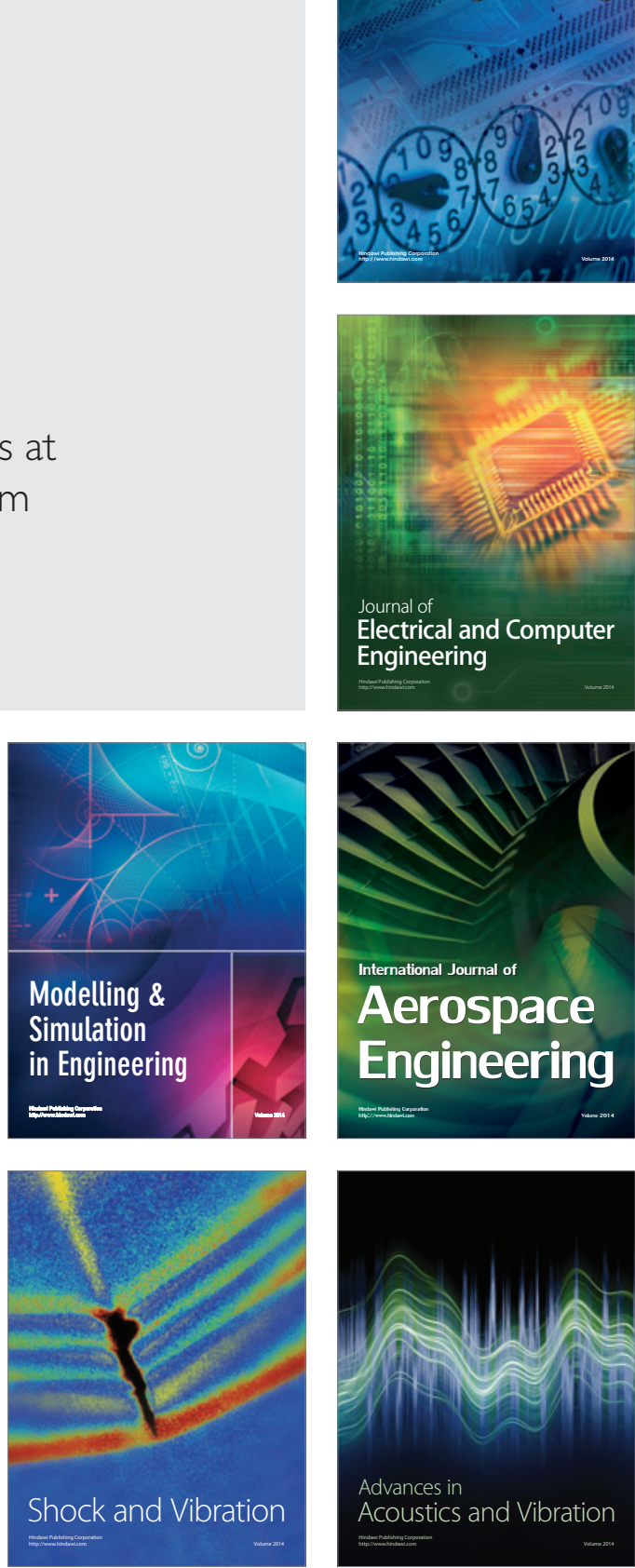